\title{
Post-Operative Complications of Ventriculoperitoneal Shunts in Children at the Children's Hospital \$ The Institute of Child Health Lahore
}

\section{Mian Awais ${ }^{1 *}$, Akhtar Munir ${ }^{1}$, Lubna Ijaz ${ }^{1}$, Muhammad Akmal Hussain ${ }^{2}$, Ihsan Ullah ${ }^{3}$, Muhammad Jahanzeb Aslam ${ }^{4}$ and Rimla Ayesha ${ }^{5}$}

${ }^{1}$ Pediatric Neurosurgery Department, The Children Hospital \$ The Institute of Child

Health, Lahore, Pakistan

${ }^{2}$ Professor, Neurosurgery Department, Allied Hospital Faisalabad, Faisalabad

Medical University, Pakistan

${ }^{3}$ Neurosurgery Department, Lady Reading Hospital Peshawar, Pakistan

${ }^{4}$ Neurosurgery Department, Allied Hospital Faisalabad, Faisalabad Medical

University, Pakistan

${ }^{5}$ Faisalabad Medical University, Faisalabad, Pakistan

*Corresponding Author: Mian Awais, Pediatric Neurosurgery Department, The Children Hospital \$ The Institute of Child Health, Lahore, Pakistan.
Received: June 18, 2021

Published: July 14, 2021

(C) All rights are reserved by Mian Awais., et al.

\section{Abstract}

Objective: Hydrocephalus is the most encountered pediatric neurosurgical abnormality, with a high prevalence in developing countries. Untreated, hydrocephalus leads to permanent disability or death. The epidemiology and outcomes of hydrocephalus treated by ventriculoperitoneal (VP) shunts in Pakistan still are not well defined and vary by region and class. The aim of this study was to determine the post operative complications of VP shunt in children presented to Department of Pediatric Neurosurgery in The Childrens Hospital \$ The Institute of Child Health Lahore.

Study Design: Retrospective cross sectional observational study.

Place and Duration of Study: Department of Pediatric Neurosurgery the Childrens Hospital \$ The Institute of Child Health Lahore from January 2020 to June 2021.

Methodology: A total of 52 children were included in this study through OPD and Neurosurgical emergency by non probability sampling. All the children were gone through CT brain and MRI brain before VP shunting.

Results: Thirteen (13) 25\% patients were presented with complications. Out of 13 patients 10 children were presented with infection $77 \%$, two (15.4\%) with malfuncting of shunt and $01(7.6 \%)$ patient with mal positioning. The mean number of surgeries performed on these patients were $1.6 \%$. All of these patients with these complications were identified with in 1 week after surgery. Conclusion: Infection was the most common pathology in children with VP shunting. The infection rate was directly proportional to the number of day patient stay in hospital. All children having hydrocephalus due to pediatric tumors or myelomeningocele presented with complications. A greater incidence of infections were observed in patients older than 2 years.

Keywords: Hydrocephalus Valve; Hydrocephalus; Ventriculo Peritoneal Shunt; Ventricul Oatrial Shunt; Early Complications 


\section{Introduction}

Ventriculoatrial (VA) and ventriculoperitoneal (VP) shunts have been used successfully for the surgical management of hydrocephalus in pediatric population in Pakistan. Ventriculoperitoneal shunt (VPS) is normally performed for the management of hydrocephalus which is a condition due to retention, excessive production or decrease clearance of cerebrospinal fluid (CSF) resulting in enlargement of the ventricular system. The main and important complication of this type of surgery is infection, which results in severe postoperative complications such fever, cognitive decline and neurological deficits. Many risk factors contribute in the development of shunt infections, such as, a history of meningitis, secondary hydrocephalus, premature babies and lack of expertise of surgical team, prolonged hospital stay, CSF leakage from wound, wound dehisence, and infection of abdominal viscera, among others.

The main bacteria responsible for shunt related infections are Staphylococcus epidermidis (52.8 to 88.9\%), Staphylococcus aureus (12 to $40 \%$ ), Gram-negative bacilli (9 to $22 \%$ ), enterobacteria, Klebsiella pneumoniae, and Pseudomonas aeruginosa [1].

Another important cause of complications is malfunctioning of the shunt valve. Obstruction of the ventricular catheter is responsible for a malfunctioning shunt. Obstruction with choroid plexus tissues, parenchymal debris and intraventricular tissue and inappropriate placement of the proximal catheter within the cerebral tissue or in the ventricular system that hinder CSF drainage [1].

VP shunt infection rates range from 0 to $31.4 \%$, with a mean of 10 to $15 \%$ [1]. Infection rates after VP shunting is higher than endoscopic third ventriculostomy, which is usually performed in selected cases of obstructed hydrocephalus.

\section{Methodology}

This observational cross sectional study was conducted in Department of Neurosurgery the Childrens Hospital \$ The Institute of Child Health Lahore from January 2020 to June 2021. A total of 52 children were included in this study through OPD and Neurosurgical emergency by non probability sampling. All the children were gone through CT brain and MRI brain before VP shunting after taking informed consent from their parents. Children with low GCS below 8 were excluded from this study.

\section{Results}

A total of 52 children were included in this study, out of which 30 children were males and 22 were female children. Age of children range from 0-13 years with mean 2.21. Distribution of age and gender as tabulated.

\begin{tabular}{|l|c|c|c|c|}
\hline Age & \multicolumn{2}{|c|}{ Males } & \multicolumn{2}{c|}{ Females } \\
\hline & Numbers & \% & Numbers & \% \\
\hline $0-2$ & 15 & 50 & 13 & 59 \\
\hline $2-7$ & 10 & 33.33 & 06 & 27.27 \\
\hline $7-13$ & 05 & 16.7 & 03 & 13.6 \\
\hline
\end{tabular}

Table 1

A total of 98 surgical procedures were performed, corresponding to 1.6 surgeries per patient. Thirteen (13) 25\% patients were presented with complications. Out of 13 patients 10 children were presented with infection $77 \%$, two (15.4\%) with mal functioning of shunt and $01(7.6 \%)$ patient with mal positioning. Signs and symptoms of infection observed after surgery are shown in table 2.

\begin{tabular}{|l|c|c|c|}
\hline Numbers & Infectious Manifestation & Number & $\mathbf{\%}$ \\
\hline 01 & Fever & 07 & 70 \\
\hline 02 & Fistula & 01 & 10 \\
\hline 03 & Pseudocyst & 01 & 10 \\
\hline 04 & Skin Erosion & 01 & 10 \\
\hline
\end{tabular}

Table 2

Analysis of the relationship between age and complications showed a significantly higher rate of infection among children older than 2 years (Table 3), a finding that is in contrast to literature data $[2,3]$.

\begin{tabular}{|l|c|c|}
\hline Age & Complications & No of Complications \\
\hline$<2$ years (n:28) & $04(14.28 \%)$ & 16 \\
\hline 2 years (n:24) & $09(37.5 \%)$ & 19 \\
\hline Total & 13 & 33 \\
\hline
\end{tabular}

Table 3 
Complications were more frequent among patients with primary hydrocephalus $(8 / 13,61 \%)$. Hydrocephalus secondary to a tumor or myelomeningocele was responsible for complications in five $(38.46 \%)$ of the 13 patients with shunt complications. However, this result was inverted when we analyzed the number of complications in relation to the total number of patients. Forty three of the 52 patients had primary hydrocephalus and only 08 of them (18.6\%) presented complications. In contrast, 09 of the 52 patients studied had secondary hydrocephalus, with complications being observed as follows (Table 4).

\begin{tabular}{|l|c|c|c|}
\hline $\begin{array}{l}\text { Cause of Hydro- } \\
\text { cephalus }\end{array}$ & Complications & $\begin{array}{c}\text { No of compli- } \\
\text { cations }\end{array}$ & Total \\
\hline $\begin{array}{l}\text { Primary Hydro- } \\
\text { cephalus }\end{array}$ & $8(18.6 \%)$ & 33 & 43 \\
\hline Melomeningocele & $3(50 \%)$ & 00 & 06 \\
\hline Tumour & $2(66.7 \%)$ & 00 & 03 \\
\hline Total & 13 & 00 & 52 \\
\hline
\end{tabular}

Table 4

Relationship between cause of hydrocephalus and complications

Complications were observed in all patients who were hospitalized for 15 days or more, with the diagnosis of complications being made, on average, at 9.3 days.

\section{Discussion}

Infection is the first and immediate postoperative complication observed in children undergoing surgery for hydrocephalus. An infection rate of $18.6 \%$ was found in our study. This value is high but still within the rates reported in the literature worldwide which ranges from 3 to $30 \%[2,3]$.

If patients with myelomeningocele and brain tumors were excluded from the present sample, the infection rate further falls to about $17 \%$.

Infection rates are much greater in these children as compared to children having congenital hydrocephalus because those children require a prolong hospital admission and most of the children develop other hospital acquired infections like pneumonia and UTIs which markedly increase the risk of shunt infections $[2,3]$. According to previous studies, $85 \%$ of shunt related infections occur within the first postoperative month and 14\% occur from the first to the 09 month postoperatively [4].
Lima., et al. [4] observed a surgical wound infection rate of $27.6 \%$ $(16 / 58)$ per procedure and of $32 \%(16 / 50)$ per patient. Almost $80 \%$ of cases being diagnosed within first month postoperatively month. Since this study was carried out for a short period, our infection rate is probably higher than observed in that study [3]. However, in view of the problems faced at public sector hospitals and considering a value of almost $10 \%$ observed in children with primary congenital hydrocephalus, this rate is acceptable [5].

In our study, all children who were admitted in hospital for more than 2 weeks developed infections of the shunt system. Although the small sample size, our study suggests that longer the duration of hospital stay is directly proportional to VPS infection by accelerating the chances of bacterial colonization. In a latest publication, Thompson., et al. [6] told that the chances of susceptibility to bacterial infection exceeds much beyond the duration of surgery. It was also observed that source of infections were not only surgical field but also exposure and cleaning of the surgical wound as well. It emphasis the need to reduce the time of hospitalization and to maintain wound care [6].

Some researchers $[5,7]$ have also observed an important relation in patient's age who are less than 6 months vs infections of the surgical wound, whose frequency was 2.6 times higher than in patients older than one year. Other literature did not find any significant difference in the infection rate between different children's ages [8]. A significant increased risk of infection was only observed among premature babies [5] in which immune system is not fully developed. In contrast to the previous studies, we found a higher predominance of complications in children from 2 to 7 years of age.

Documented risk factors for Ventriculo peritoneal shunt infection as reported by multiple studies, include premature babies, young age [9-11], CSF fistula [11], holes in gloves during shunt handling [11], previous shunt infections and intraventricular hemorrhage [10].

\section{Conclusion}

Shunt malfunctioning is a common neurosurgical problem in children with VP shunts, often leading to frequent and sometimes prolong hospital stays. Although there have been repeated and frequent developments to decrease rates of shunt malfunctioning, such as antibiotic impregnated catheters, sterile handling of shunts and programmable shunt valves, patients with VP shunting for hydrocephalus commonly require multiple shunt revision surgeries 
throughout their life. To prevent morbidity, early detection and proper management are key. Shunt infections in premature babies remains to be a serious problem due to underdeveloped immune system makes these patients especially prone to bacteria. With progressive advancements in shunt valve systems and infection prevention, morbidity from VP shunt complications may continue to be reduced.

\section{Bibliography}

1. Sarguna P and Lakshmi V. "Ventriculoperitoneal shunt infections". Indian Journal of Medical Microbiology 24 (2006): 5254.

2. Pople IK., et al. "Infection of cerebrospinal fluid shunts in infants: a study of etiological factors". Journal of Neurosurgery 77 (1992): 29-36.

3. Drake JM., et al. "Randomized trial of cerebrospinal fluid shunt valve design in pediatric hydrocephalus". Neurosurgery 43 (1998): 294-303.

4. Lima MMM., et al. "Infecções em dispositivos neurológicos implantáveis em crianças e adolescents". Arquivos de Neuropsiquiatria 65 (2007): 118-123.

5. Kulkarni AV., et al. "Cerebrospinal fluid shunt infection: a prospective study of risk factors". Journal of Neurosurgery 94 (2001): 195-201.

6. Thompson DN., et al. "Shunt infection: is there a near-miss scenario?". Journal of Neurosurgery 106.1 (2007): 15-19.

7. Dallacasa P., et al. "Cerebrospinal fluid shunt infections in infants". Child's Nervous System 11 (1995): 643-648.

8. Faillace WJ. "Shunt infection". Journal of Neurosurgery 94 (2001): 1019-1020.

9. MJ McGirt., et al. Pediatric Neurosurgery 36 (2002): 248-255.

10. TD Simon., et al. Journal of Neurosurgery: Pediatrics 4 (2009): 156-165.

11. AV Kulkarni., et al. Journal of Neurosurgery 94 (2001): 195201.

\section{Volume 4 Issue 8 August 2021}

(C) All rights are reserved by Mian Awais., et al. 